\title{
PERSONALIDAD, CULPABILIDAD Y RETRIBUCIÓN DE LA LEGITIMACIÓN Y FUNDAMENTACIÓN ÉTICO-JURÍDICA DE LA PENA CRIMINAL
}

\author{
DR. URS KINDHÄUSER* \\ Universidad de Bonn
}

\begin{abstract}
RESUMEN: También un sistema jurídico justo requiere de sanciones para salvaguardar su propia estabilidad. Puesto que lo específico de la pena criminal se halla en un reproche ético-jurídico, esta forma de sanción ha de ser ético-jurídicamente legítima, esto es, justa tanto como institución cuanto como consecuencia jurídica concreta. Mas la pena solo puede ser justa si ella sirve a la retribución de culpabilidad por un comportamiento que expresa una falta grave de humanidad.
\end{abstract}

Palabras clave: pena, justicia, culpabilidad, personalidad.

ABSTRACT: A just legal system also requires sanctions in order to safeguard its own stability. Due to the fact that a legal- ethical reproach is specific to criminal punishment, this form of sanction has to be legitimated form a legal-ethical approach. This means fair; both as an institution and as a concrete legally consequence. But the punishment can only be just if it suits the retribution of culpability for a behaviour that denotes a serious lack of humanity.

Key words: punishment, justice, culpability, personality.

\section{PLANTEAMIENTO DEL PROBLEMA}

Toda reflexión acerca de la legitimación y delimitación ético-jurídica de la pena criminal presupone una respuesta a la pregunta semántica acerca del significado de la palabra "pena". La respuesta reza: "pena" significa la irrogación de un mal como expresión de la desaprobación de un comportamiento previo defectuoso ${ }^{1}$. De faltar alguno de estos elementos a la acción estatal en cuestión, entonces no puede reconocerse en ella una sanción en el sentido del derecho penal. A modo de ejemplo: la aplicación de coacción inmediata a través de la operación de un carro lanzaaguas ciertamente constituye la irrogación estatal de un mal, pero no una pena, ya que de acuerdo a su forma la reacción en cuestión no expresa reproche alguno.

Un intento de legitimar la pena ha de tener en cuenta cada uno de los elementos de la definición enunciada. Puesto que se trata aquí de la justificación de una institución

\footnotetext{
* El autor es Doctor en Derecho por la Universidad de Friburgo. Asimismo, se ha desempeñado como profesor en las cátedras de Derecho Penal y Derecho Procesal Penal (1995), Director del Instituto de Derecho Penal de la Universidad de Bonn (desde 1996), y Decano y Prodecano de la Facultad de Ciencias Jurídicas y del Estado de la Universidad de Bonn (2002/2003 y 2003/2004, respectivamente). El año 2008, la Universidad de Piura (Perú) le otorgó el grado de profesor honorífico por esa casa de estudio. Agradecemos al profesor Juan Pablo Mañalich quien ha facilitado este artículo para la presente edición de Derecho y Humanidades.

${ }^{1}$ El mal consiste aquí, tal como HOERSTER, Norbert. Zur Begründung staatlichen Strafens [Fundamentación de la práctica punitiva del estado], en: KRAWIETZ, W. Theorie der Normen [Teoría de las normas]. Berlin: Festgabe für Ota Weinberger, 1984, p. 225, lo formula acertadamente: "en algo distinto de coacción a la reparación de un perjuicio eventualmente producido".
} 
jurídica, y puesto que el criterio de corrección jurídica es la justicia, un tal intento de legitimación tiene que demostrar que puede ser justo reprochar a alguien, a través de la irrogación de un mal, un comportamiento defectuoso; aunque enfatizando aquí: que puede ser justo. Pues incluso de alcanzarse a justificar la pena criminal como tal, con ello poco se habrá ganado en cuanto a la legitimidad de los tipos penales efectivamente vigentes. La legitimidad de la pena solo es condición necesaria, mas no condición suficiente, de la legitimidad de determinadas normas de sanción específicas. Un intento de legitimación de la pena ha de responder todavía la pregunta de si bajo el presupuesto de que la pena sea éticamente legítima también ha de ser éticamente legítimo seleccionar y penalizar determinadas formas de comportamiento de entre todas las formas posibles de comportamiento jurídicamente defectuoso.

En lo que sigue han de considerarse ambos problemas de fundamentación, y el resultado proveerá una base para la crítica de ciertas tendencias de la política criminal contemporánea.

\section{DE LA LEGITIMACIÓN DE LA PENA}

\subsection{NORMAS DE COMPORTAMIENTO JUSTAS}

La pena solo es legítima si también lo son las normas de comportamiento reforzadas punitivamente; responder con una irrogación retributiva de un mal a la contravención de una exigencia de conducta que sea éticamente deficitaria sería eo ipso ilegítimo. Sin embargo, en nuestro contexto no es necesario entrar en la pregunta de si las normas tienen que ser éticamente legítimas para así tener ya el carácter de normas jurídicas. Aun si uno, a la manera del positivismo, separa nítidamente derecho y moral según su respectiva base y modo de validez, subiste la necesidad de introducir un criterio para la evaluación de la corrección del derecho positivo. Uno de los argumentos más potentes a favor del positivismo consiste, en efecto, en que solo bajo una diferenciación entre derecho y moral el primero se vuelve susceptible de crítica ética ${ }^{2}$.

Lo jurídicamente correcto, en atención a la semántica de la palabra "bueno", puede ser evaluado en tres niveles ${ }^{3}$. En el primer nivel se trata del significado instrumental de "bueno", de lo que es "bueno para algo". Las condiciones de lo bueno son aquí indiferentes frente al fin en cuestión; uno habla de racionalidad de fines. En el segundo nivel de legitimación se tematiza la bondad del fin mismo, y ya desde una perspectiva sociopragmática. La norma tiene que ser, en tal medida, "buena" en el sentido de "buena para alguien", esto es: ventajosa. Si esta noción de bondad se interpreta sobre la base del utilitarismo, ella puede ser referida a la utilidad total o a la utilidad promedio de los

\footnotetext{
${ }^{2}$ Véase HART, H.L.A. Recht und Moral. Göttingen, Alemania: Vandenhoeck \& Ruprecht Verlag, 1971, pp. 17 ss.

3 Véase aquí también HÖFfE, Otfried. Politische Gerechtigkeit, Grundlegung einer kritischen Philosophie von Recht und Staat [Justicia política, fundación de una filosofía crítica del derecho y el estado]. Frankfurt, Alemania: Suhrkamp, 1987, pp. 52 ss.
} 
miembros de la sociedad 4 . El criterio propio del tercer nivel de legitimación es "bueno" en el sentido de "bueno en sî". Esta noción de bondad se deja explicar, por referencia a formas de comportamiento, en el sentido de una estricta universalización de máximas de acción, donde para la introducción de la generalización se hallan a disposición, al modo de un modelo teórico, las metáforas del punto de vista moral y del contrato social, esta última portadora de mayor rendimiento explicativo en el contexto que aquí interesa 5 . Puesto que la necesidad del derecho resulta de la coordinación requerida para el libre desenvolvimiento de los individuos, el principio legitimador de la estricta universalización tiene que asegurar la compatibilidad de la libertad de cada cual con la libertad de cada uno de los demás para la mayor ventaja de todos. Dado que el principio de la estricta universalización no tolera ganancia particular unilateral de libertad alguna, el mismo admite ser designado como principio de favorabilidad recíproca o distributiva. Este criterio de corrección jurídica en el nivel superior de legitimación, que es inmune frente a los criterios propios de los niveles inferiores, será llamado justicia ${ }^{6}$.

El criterio de justicia de la coexistencia de libertad ventajosa para todos conduce a que el carácter vinculante del deber-ser quede libre de todo momento coactivo. Yo puedo aceptar una exigencia de comportamiento que desde el punto de vista de la libertad trae más ventajas que desventajas para mí, y si puedo aceptarla entonces a ella falta el momento de la coacción como momento de pérdida de libertad.

\footnotetext{
${ }^{4}$ Acerca del utilitarismo véase Frankena, William. Analytische Ethik [Ética analítica]. München, Alemania: Deutscher Taschenbuch Verlag, 1972, pp. 54 ss.; HÖFFE, Otfried (coord.). Einführung in die utilitaristische Ethik [Introducción a la ética utilitarista]. München, Alemania: Klassische und zeitgenössische Texte, Beck, 1975; HoERSTER, Norbert. Utilitaristische Ethik und Verallgemeinerung [Ética utilitarista y generalización]. Freiburg/München, Alemania: Verlag Karl Alber, 1971; MACKIE, John. Ethik [Ética]. Alemania: Reclam Universal-Bibliothek,1981, pp. 157 ss.

${ }^{5}$ El concepto del punto de vista moral designa el punto de vista de un juzgador independiente, desprejuiciado, imparcial, objetivo, desapasionado y neutral; véase BAIER, Kurt. Der Standpunkt der Moral [El punto de vista de la moral]. Düseldorf, Alemania: Patmos Verlag, 1974, p. 191. - Acerca de las nuevas teorías del contrato social véase BuCHANAN, James. Die Grenzen der Freiheit [Los limites de la libertad]. Mohr Siebeck, 1984; NozICK, Robert. Anarchie, Staat, Utopia [Anarquí, Estado y Utopia]. Frankfurt, Alemania: Moderne Verlagsgesellschaft 1976; RAWLS, John. Eine Theorie der Gerechtigkeit [Teoría de la Justicia]. Alemania: Suhrkamp, ,1975. - Acerca de las similitudes de ambos modelos véase en particular Koller, Peter. "Theorien des Sozialkontrakts als Rechtfertigungsmodelle politischer Institutionen [Teorías del contrato social como modelos de justificación de instituciones políticas]”, en: Theorie der Normen [Teoría de las normas]. Berlín, Alemania: Festgabe für Ota Weinberger, 1984, pp. 241 ss.; el mismo, Neue Theorien des Sozialkontrakts [Nuevas teorías del contrato social]. Alemania: Dunker und Humblot, 1987, pp. 243 ss. y passim.

${ }^{6}$ La libertad es entendida aquí como un bien (necesariamente) negativo-cooperativo, esto es, como un bien que recién cobra existencia a través de una renuncia recíproca a su afectación. La universalización se halla referida a este bien negativo-cooperativo y no así a bienes (contingentemente) positivo-cooperativos, que son producidos a través de trabajo conjunto. El trabajo conjunto en la producción de un bien tal, que depende de la fijación arbitraria de un fin, solo puede exigirse legítimamente de aquel que se beneficia de la utilidad correspondiente; véase también infra, nota 14. Sobre la demarcación entre principios morales y el principio de utilidad véase SINGER, Marcus. Verallgemeinerung in der Ethik Zur Logik moralischen Argumentierens [Generalización en la ética, hacia una lógica en la argumentación moral]. Frankfurt a. M., Alemania: Deutsch Suhrkamp, 1975, pp. 215 ss. -Con la distinción entre libertad y bienes positivo-cooperativos se puede obtener una de las posibles diferenciaciones entre el fin de protección de las normas de comportamiento reforzadas mediante pena criminal (coexistencia elemental de libertad) y el fin de protección de las normas de comportamiento del derecho de contravenciones (seguridad y bienestar), véase WOLFF, Erik, FESTSCHR, Frank II, 1930, pp. 516 ss. -Acerca de la relación entre el concepto de felicidad y la libertad, de un lado, así como de la relación entre el principio de justicia con otros principios de la interacción social (solidaridad y otros), véase HöfFE, Otfried, op. cit. (n. 3), pp. 300 ss., 306 ss., 386 ss., así como 469 ss.
} 
Las libertades concretas no tienen por qué ser apreciadas uniformemente por todos. Alguno pondrá la vida, otro el honor o el bienestar, por ejemplo, en la cúspide de sus preferencias. Este problema se deja resolver, sin embargo, si uno concibe las renuncias de libertad recíprocas para la obtención de mayor libertad para todos al modo de un intercambio de anillos de compromiso ${ }^{7}$. Como contraprestación a la propia renuncia al menoscabo de concretas libertades ajenas, uno obtiene la renuncia ajena al menoscabo de la libertad más apreciada por uno mismo. En el marco de una tal legitimación de normas, extensivamente abierta desde el punto de vista del individuo y exclusivamente referida a un sistema de libertades básicas, es posible prescindir de asunciones antropológicas para la justificación ética del derecho, tal como la problemática tesis de Hobbes acerca de una supuesta voluntad incondicionada de supervivencia del ser humano ${ }^{8}$. Que ulteriormente también sea necesario un conjunto de normas secundarias, cuya legitimidad ha de derivarse del posibilitamiento o aseguramiento del sistema de libertades fundamentales, es algo que se entiende de suyo. Ahora bien, hace más de un siglo que la protección de bienes jurídicos es irrestrictamente reconocida como criterio de legitimación de normas de comportamiento. Lo que aquí interesa es que el concepto de bien jurídico admite ser extraído sin más de una teoría de la justicia contractualista. De conformidad con esto, son bienes jurídicos aquellas propiedades de seres humanos, cosas e instituciones que sirven al libre desenvolvimiento individual y que resultan merecedoras de protección bajo el principio de la coexistencia de libertad ventajosa para todos. No puede ser obviado, sin embargo, que en el marco de la política criminal contemporánea la protección de bienes jurídicos se halla orientada de modo puramente utilitarista ${ }^{9}$, de manera tal que un amplio conjunto de normas no satisface el criterio de legitimación del tercer nivel. Ejemplos crasos de esto son las prohibiciones, jurídico-penalmente reforzadas, de la infracción de deberes relativos a la conservación de libros contables de venta $(\$ 283 \mathrm{~b}$ StGB) y el porte de vestimenta de un mismo color para la demostración de una convicción política común en el marco de una concentración o asamblea ( $\$ \$ 3,28$ de la ley de asambleas).

\subsection{DÉFICIT DE REALIZACIÓN}

Las normas ventajosas para todos son inestables, puesto que, aunque pueda sonar paradójico, es individualmente más ventajoso quebrantarlas que seguirlas. Pero si todos las quebrantan, entonces cada uno pierde la ventaja que el seguimiento de la norma trae consigo, poniéndose así en peor situación que de haber sido seguida la norma.

\footnotetext{
7 Véase HÖFFE, Otfried, op. cit. (n. 3), pp. 393 s.

${ }^{8}$ El miedo a la muerte y la búsqueda de placer son "las pasiones" que, según Hobbes, "disponen al ser humano para la paz”, véase HоввES, Thomas. Leviathan. Editado por Iring Fetscher Frankfurt a. M, Alemania, Suhrkamp, 1984, p. 98. Sobre las relaciones entre antropología social, derecho y libertad véase también NAUCKE, Wolfgang. Rechtsphilosophische Grundbegriffe [Conceptos básicos de filosofía del derecho]. -2a ed.- Alemania: Luchterhand Verlag, 1986, pp. 121 ss.; BARTUSCHAT, Wolfgang, en: HÖFFE (coord.). Thomas Hobbes, Anthropologie und Staatsphilosophie [Thomas Hobbes, Antropología y filosofía del estado]. Freiburg, Alemania, 1981, pp. 19 ss. - En lo demás, es correcto distinguir entre las condiciones (normativas) de la justificación del derecho y las condiciones (descriptivas) de su concreción y aplicación; al segundo ámbito corresponden inequívocamente, entre otros, datos antropológicos.

9 Acerca del vacío conceptual de la protección de bienes jurídicos en la actualidad acertadamente LÜDERSSEN, Klaus. Die Krise des öffentlichen Strafanspruchs [La crisis de la acción penal pública]. Frankfurt, Alemania: Würzburger Vorträge zur Rechtsphilosophie, Rechtstheorie und Rechtssoziologie Heft 10, 1989, ap. A) I.1.
} 
Este círculo vicioso se deja ilustrar de la mano del conocido dilema del prisionero ${ }^{10}$ : dos detenidos son mantenidos aisladamente en custodia como sospechosos de un crimen capital. Ambos saben que, en caso que ninguno de los dos confiese, pueden ser condenados a nada más que una pena de prisión de un mes, por un delito de vagancia. Si, en cambio, solo uno de ellos confiesa, entonces este (como testigo principal) habrá de quedar libre, mientras que el otro resultará penado por el delito capital con una privación de libertad de diez años. Pero si ambos declaran inculpatoriamente, entonces la pena se reduce a cinco años para cada uno a consecuencia de la confesión. Si se busca la máxima de acción favorable para todos, entonces es claro: ambos tienen que callar, puesto que así ellos pueden esperar una pena considerablemente más baja que en caso que de una confesión bilateral. Mas existe una posibilidad de ponerse en una situación aún mejor: si uno confiesa y el otro calla, entonces este resulta eximido a costa del otro, quien así será sancionado con la pena más alta. Sin embargo, este resultado individualmente óptimo se deja alcanzar exclusivamente en caso que el otro se atenga unilateralmente a la máxima de acción que es ventajosa para todos.

Si ninguno de los detenidos sabe cómo decidirá el otro, y sin que entren en juego motivos altruistas, se da una instancia de lo que se entiende como decisión bajo incertidumbre, para la cual existen dos reglas (de igual valor): de conformidad con la regla optimista de decisión maximax, ha de darse por supuesta la situación más favorable, mientras que bajo la regla pesimista de decisión maximin ha de buscarse obtener el mayor provecho posible de la situación menos favorable ${ }^{11}$. Lo distintivamente problemático del dilema del prisionero es el hecho de que la aplicación de cada una de ambas reglas conduce a un resultado inferior al óptimo, esto es, a un resultado peor que el que podría ser alcanzado. Si cada uno de los hechores asume optimistamente que el otro callará, entonces cada uno será sancionado con una pena de cinco años. Si cada uno de ellos asume pesimistamente, en cambio, que el otro confesará, entonces él mismo tendrá que confesar, para así evitar ser sancionado con la pena más alta, con lo cual también recibirá la pena de cinco años. La máxima favorable para todos, consistente en callar para así ser condenado a nada más que un mes de cárcel, resulta inestable bajo la condición de incertidumbre recíproca. En esta medida, el dilema del prisionero se corresponde con la situación de decisión del estado de naturaleza hobbesiano ${ }^{12}$.

El establecimiento normativo de máximas de acción distributivamente ventajosas es insuficiente por sí solo ${ }^{13}$. Resulta asimismo necesario, precisamente, crear certeza en el sentido de confianza fundamentada en cuanto a que todos -o bien, tratándose de un amplio número de destinatarios, casi todos- seguirán la norma. Bajo ninguna circunstancia puede existir el peligro de que el sujeto leal a la norma obtenga una doble pérdida

\footnotetext{
${ }^{10}$ Véase RAWLS, John, op. cit. (n, 5), pp. 302 ss., con fundamentos ulteriores.

11 Sobre esto véase HÖFFE, Otfried, op. cit. (n. 3), p. 422; RAWLS, John, op. cit. (n. 5), pp. 176 ss., con fundamentos ulteriores.

12 Véase HobBes, Thomas, op. cit. (n. 8), pp. 104 ss.

13 Ya a través del establecimiento de normas son suprimidos algunos defectos de realización de máximas de acción racionales en sentido práctico, a saber, la falta de determinación objetiva del contenido y la falta de estabilidad en el tiempo; sobre esto véase KINDHÄUSER, Urs. Zwang, en Staatslexikon, Auflage, No 7, Freiburg, Alemania: 1989, columnas 1178 ss.
} 
mientras que el quebrantador de la norma una doble ventaja, a saber, que el sujeto leal a la norma haga posible, contribuyendo con una renuncia de libertad y siguiendo la norma, que él mismo sufra un menoscabo ulterior en su libertad, mientras que el quebrantador de la norma, al no contribuir con una renuncia de libertad, amplíe aún más su espacio de libertad. La norma ventajosa para todos obtiene su carácter ventajoso solo ahí donde el "freeriding", que es la alternativa individualmente más ventajosa a costa de otros, resulta en lo posible excluido. Puesto que el impedimento del "freeriding" es distributivamente ventajoso y con ello susceptible de consenso general, la imposición -en particular coercitiva- del reconocimiento de normas justas como razones eficaces para la acción deviene, en principio, éticamente legítima ${ }^{14}$.

\subsection{PENA Y COACCIÓN}

Con el hallazgo de que sin una posibilidad de imposición general las normas justas son inestables, resulta excluida, al mismo tiempo, la plausibilidad de una interpretación exclusivamente preventivo-especial de la pena criminal ${ }^{15}$. En la medida en que para todos es ventajoso quebrantar la norma, la evitación del quebrantamiento de la norma no puede constituir un fin educativo específicamente referido al autor. Las medidas preventivoespeciales pueden ser conceptuadas, a lo sumo, como parte dependiente de una noción de pena a ser determinada de otro modo, y se vuelven significativas recién allí donde la validez de la norma quebrantada por el autor ya es estable.

(Solo entre paréntesis ha de advertirse que una teoría de la pena justa es un elemento de una teoría de la justicia política. La pena justa ha de ser cubierta por una estrategia de humanidad ${ }^{16}$, que ha de perseguir una justa distribución de bienes y posibilidades de desenvolvimiento. En el contexto de relaciones sociales injustas no hay espacio para la estabilización de la validez de normas mediante pena.)

El principio que personas racionales escogerían en la situación imaginaria de un contrato social sería un principio de prevención general. Es racional y ventajoso para todos adoptar medidas bajo las cuales el quebrantamiento de una norma no resulta conveniente, y ya para nadie ${ }^{17}$. A la prevención general se objeta que ella no proveería seguridad alguna en cuanto a la protección del inocente, en el sentido de quien nada tiene que ver con el hecho, frente a la pena ${ }^{18}$. Esto constituye un error, sin embargo, una vez que la

\footnotetext{
${ }_{14}$ Con ello no está excluido que también la imposición de normas que solo satisfacen el criterio de legitimación utilitarista del segundo pudiera tener lugar coercitivamente. Antes bien, esto es sin más posible en los casos en que el destinatario de la norma se beneficia de esta sin contribuir con su respectiva prestación. Pero entonces la coacción -tal como en el derecho de las contravenciones- ha de estar libre de reproche ético que descanse en principios de justicia.

15 Para una aguda defensa de la misma véase sin embargo BAURMANN, Michael. Zweckrationalität und Strafrecht, Argumente für ein tatbezogenes Maßnahmerecht, [Racionalidad instrumental y derecho penal]. Opladen, Alemania: Westdeutscher Verlag, 1987, pp. 25 ss.

16 Véase aquí HöFfe, Otfried. Zur Ethik öffentlicher entscheidungsprozesse [Hacia una ética en los procesos de decisión pública], en Alber - Reihe: Praktische Philosophie, Strategien der Humanität, Freiburg: München, 1975, pp. 316 ss. y passim; RAWLS, John, op. cit. (n. 5), pp. 291 ss.

17 Véase RaWls, John, op. cit. (n. 5), pp. 272 s., 349 s., 624 s.

18 Recientemente GÖsSEL, Karl Heinz, FestSChr. f. Pfeiffer, 1988, p. 17: “También la irrogación preventiva de un mal solo pretende incidir en el futuro sin depender de que hayan sido cometido hechos punibles".
} 
prevención general es entendida como teoría de la pena, puesto que el concepto de pena implica ya un comportamiento previo defectuoso. Una reacción estatal que ni siquiera exige el convencimiento (de un juez) acerca de la efectividad del quebrantamiento de una norma no representa pena alguna, sino una forma alternativa -más allá de cómo pueda ser fundamentada- de violencia. Adicionalmente se afirma, de otra parte, que la prevención general no proveería seguridad alguna en cuanto a la protección frente a la pena de quien es inocente en el sentido (distinto) de quien no es, en definitiva, responsable del hecho ${ }^{19}$. Esto no vale, sin embargo, para una teoría de la prevención general que satisface el criterio de legitimación de la favorabilidad para todos. Una persona racional solo aprobará la imposición de una norma a través de la irrogación de un mal en la medida en que esté garantizado que esta irrogación de un mal sea evitable a través del seguimiento de la norma. Una teoría de la prevención general éticamente legítima encierra así, necesariamente, tanto el principio del hecho como el principio de evitabilidad.

No obstante lo anterior, a la prevención general, en su comprensión tradicional de la pena como medio de intimidación, han de dirigirse otras objeciones de peso, de las cuales tienen que ser enunciadas a lo menos tres. De partida: ella no reconoce conexión interna alguna entre el peso específico de la norma quebrantada y el marco penal correspondiente. No sería ilegítimo, a modo de ejemplo, sancionar más severamente delitos frecuentes de menor gravedad que crímenes capitales cometidos muy ocasionalmente. También existe el peligro de que, por temor de una intimidación lo más efectiva posible, defectos en la indagación policial de crímenes sean compensados con una intensificación de la irrogación del mal correspondiente. Adicionalmente, la intimidación es un efecto causal que depende de variables contingentes, entre las cuales también cabe considerar el cálculo altamente subjetivo de costo-beneficio practicado por el autor, el cual a su vez puede estar decisivamente influenciado por la asunción de que él no será descubierto. Con esto, empero, justamente en el ámbito de normas elementales para la coexistencia de libertad recíproca la intimidación constituye un factor de estabilización de muy poco peso. Finalmente, mediante una amenaza de pena solo puede ser intimidado quien al momento del hecho actúa con conocimiento de la punibilidad de su comportamiento, lo cual excluye al autor que actúa imprudentemente o bien sin conciencia de la antijuridicidad. Con ello no está dicho que un actuar en tal medida deficitario deba ser punible, lo cual equivaldría a una petitio principii; solo se trata de llamar la atención sobre la circunstancia de que la difícil comprobación del dolo y de la conciencia de la antijuridicidad puede llevar a suposiciones inaceptables que -tal como la antigua presumtio doli ${ }^{20}$ - en general desacreditan el concepto de pena intimidatoria.

Como nota al margen -por no pertenecer al tema- ha de apuntarse que la teoría de la intimidación a lo sumo resulta adecuada para proveer un fundamento practicable y al mismo tiempo legítimo al así llamado derecho de contravenciones [Ordnungswidrigkeitsrecht $]^{21}$.

\footnotetext{
19 Véase HART, H.L.A., op. cit. (n. 2), pp. 76 s.; véase también BURKHARDT, GA 1976, pp. 336 s.

20 Véase HRUSCHKA, JZ 1987, p. 167.

21 Véase supra nota 14; sobre esto también KINDHÄUSER, Urs, Gefährdung als Straftat [Puesta en peligro como delito], Klostermann, Alemania: Vittorio, 1989, pp. 343 ss.
} 


\subsection{PERSONALIDAD Y CULPABILIDAD}

Antes de considerar la pregunta de si la teoría de la prevención general se deja modificar de modo tal que ella resulte inmune a las objeciones ya enunciadas, es oportuno atender desde ya a un punto importante: la teoría de la intimidación no es una teoría que explique todos los elementos del concepto de pena. Ella no contiene una fundamentación para el elemento de la desaprobación (ética) del autor. Aquí el momento del reproche es tan superfluo como en la coacción de ejecución (o cumplimiento forzado) del derecho civil o del derecho administrativo, en la medida en que la pena solo sirva al fin de imponer psíquicamente el seguimiento de la norma a través de la conminación e irrogación de un mal ${ }^{22}$. Puesto que la explicación hoy dominante de la culpabilidad como reprochabilidad no es más que una reformulación positivistamente operada del principio de evitabilidad en términos de la no-satisfacción de causas de inculpabilidad y exculpación legalmente fijadas, se vuelve necesaria una determinación del contenido del concepto de culpabilidad, que aquí ha de ser traída a la siguiente fórmula: culpabilidad es una falla personal que lesiona el sentido de la justicia de un modo que produce indignación. A esta fórmula subyace la tesis de que el sentido de la justicia constituye un elemento esencial del concepto de la persona éticamente responsable y que este concepto de persona moral es asimismo constitutivo para la idea de una coexistencia de libertad ventajosa para todos -esto es, para el derecho. Esta tesis será con la brevedad aquí impuesta- desarrollada más de cerca.

Después de que, desde Kant, la noción de contrato social en cierta medida pareciera haberse ido a la ruina, ella ha vuelto a figurar, desde hace apenas dos decenios, entre las metáforas más fundamentales de la filosofía jurídica y política ${ }^{23}$, y ello por buenas razones. El contrato justo cuenta como símbolo de la obtención de libertad para todas las partes a través de su vinculación recíproca. Puede en todo caso dudarse si, tal como Rawls lo sostiene, los principios de justicia se dejan desarrollar recién a partir de la obtención de un acuerdo por parte de personas racionales ${ }^{24}$. Podría ser el caso, antes bien, que ya la aparición de una situación contractual exija la satisfacción de principios de justicia ${ }^{25}$. Quien pretende tratar contractualmente con otro renuncia ya a la libertad de coaccionarlo, reconociéndolo al instante como persona con quien se pueden formular principios vinculantes para la vida en común. Por ello, la asunción de que el cosujeto es una persona con sentido de la justicia es ya presupuesto de toda vinculación recíproca.

Ahora bien, ¿qué condiciones ha de satisfacer alguien para ser reconocido como contraparte de un contrato, como personal moral? Aquí cabe enunciar seis condiciones

\footnotetext{
22 Puesto que a la multa del derecho de contravenciones falta el momento del reproche, ella puede ser legitimada sobre la base del concepto de intimidación. Ahora bien, con ello el concepto de culpabilidad del derecho de contravenciones no solo resulta ser más pobre de contenido que el de la pena criminal, sino también cualitativamente distinto de este; recientemente al respecto TIEDEMANN, NJW 1988, p. 1172.

${ }^{23}$ Véase supra, n. 5.

${ }^{24}$ Véase RAWLS, John, op. cit. (n. 5), pp. 34 ss. y passim.

25 Véase también Bubner, Rüdiger. Handlung, Sprache, Vernunft, [Acción, lenguaje, razón]. Verlag, Alemania: Suhrkamp 1982, pp. 287 s.; HÖFfE, Otfried. Ethik und Politik [Ética y politica]. Frankfurt, Alemania: Suhrkamp Taschenbuch Wissenschaft, 1979, pp. 227 ss.
} 
necesarias ${ }^{26}$ : personas en este sentido son, en primer lugar, seres racionales, a quienes se adscriben, en segundo lugar, predicados intencionales y respecto de quienes uno asume, en tercer lugar, una actitud intencional. Esto último significa que uno se empeña en entender el comportamiento de una persona en razón de los propósitos, sentimientos, conocimientos, etc., que a ella se adscriben. De una persona moral uno espera, en cuarto lugar, que ella replique la adopción de esta actitud intencional. Frente a personas morales cabe formarse, de este modo, intenciones de segundo orden, esto es, intenciones referidas a intenciones. Esta reciprocidad de las actitudes intencionales es a su vez presupuesto de la quinta condición, consistente en ser capaz de formarse intenciones de tercer orden, y así sucesivamente. Tales intenciones de orden superior son presupuesto de la comunicación verbal, tal como lo muestra un ejemplo sencillo: si yo pretendo advertir al oyente $\mathrm{O}$ sobre mi perro con las palabras "este perro muerde", entonces este acto de habla solo es exitoso si (i) yo tengo la intención de que $\mathrm{O}$ muestre una determinada reacción (que se mantenga alejado del perro); si (ii) O cree que yo tengo la intención de producir esta reacción en él; y si (iii) $\mathrm{O}$ reacciona conscientemente, porque él cree que yo pretendo provocar esa reacción en él.

Pero para que alguien pueda ser reconocido como contraparte en un contrato, él ha de satisfacer aún una sexta condición: él tiene que ser tenido por capaz de mantener intenciones de primer orden, consciente y voluntariamente, como eficaces para la acción. Lo que esto significa se deja ejemplificar de la mano de la situación del otorgamiento de una promesa ${ }^{27}$ : si yo prometo a $\mathrm{O}$ que lo visitaré a las tres de la tarde del día siguiente, con ello expreso que quiero tener una determinada intención en un determinado punto de tiempo y que $\mathrm{O}$ puede confiar en que yo, puesto que así lo he prometido, daré prioridad a esta intención frente a otras posibles intenciones, por ejemplo: leer un libro o dar un paseo. La capacidad de dar prioridad a una intención sobre otras intenciones (potenciales) en atención a razones normativas admite ser denominada, siguiendo a Frankfurt ${ }^{28}$, libertad de voluntad. A favor de la asunción de la realidad de una tal forma de libertad de voluntad hablan a lo menos tres razones. La primera: la capacidad de disponer, de modo eficaz para la acción, sobre propias intenciones es, tal como la autoconciencia, una experiencia inmediata de todo agente ${ }^{29}$. La segunda: la transferencia a cosujetos de la autoexperiencia de poder disponer, con eficacia para la acción, sobre propias intenciones, es presupuesto necesario de toda cooperación social de seres humanos que no actúan por mero instinto. Y la tercera: la experiencia cotidiana muestra que los contratos son de hecho mantenidos y observados, pues de lo contrario esta institución no existiría.

Se preguntará ahora por qué las seis condiciones enunciadas solo son necesarias, y no suficientes, para el concepto de persona moral. La respuesta es fácil. No existe examen

\footnotetext{
26 Para lo que sigue véase DENNETT, Daniel. Bedingungen der Personalität [Condiciones de la personalidad]. En: SIEP, Ludwig (ed.). Identität der Person [Identidad de la persona]. Alemania: Basel-Stuttgart: Schwabe, 1983, pp. 21 ss.; acerca de las consecuencias de este análisis para la construcción del delito véase KINDHÄUSER, Urs, op. cit. (n. 21), pp. 29 ss., 41 ss.

${ }^{27}$ Acerca de esto véase SEARLE, John. Sprechakte [Actos de habla]. Frankfurt, Alemania: Suhrkamp Verlag, 1983, pp. 88 ss.

28 Journal of Philosophy, Columbia University, No 68, Nueva York, Estados Unidos, 1971, pp. 5 ss.

29 Exhaustivamente al respecto SEARLE, John. Geist, Hirn und Wissenschaft [Mentes, cerebros y ciencia]. Frankfurt, Alemania: Suhrkamp, 1986, pp. 86 ss.
} 
alguno cuyo objeto sea la comprobación de tales condiciones y cuyo resultado positivo sea la inclusión de alguien en el círculo de personas responsables. El reconocimiento de otro como persona moral, esto es, como sujeto que puede satisfacer prestaciones obligatorias, implica un abierto depósito de confianza por una parte, al cual corresponde una asunción de esta confianza por la otra. Hasta que se produzca el cumplimiento del deber correspondiente puede haber razones para no otorgar esta confianza a otro, por ejemplo, si el individuo en cuestión es un niño o alguien que sufre de un trastorno mental. Pero no hay garantía positiva alguna de que el otro sea una persona moral ${ }^{30}$. De esto se siguen, para el caso del incumplimiento de una obligación, dos posibilidades. Uno puede, de un lado, privar al afectado de la cualidad de persona moral; él ha de ser tratado, en consecuencia, con el cuidado que requiere un niño o alguien que padece de un trastorno mental. Pero uno también puede mantenerse en la atribución de personalidad moral al individuo en cuestión, con la consecuencia de que este ha de responder por la infracción de deber como una falla personal y -en el contexto de la vida cotidiana- "disculparse" por la confianza injustificadamente pretendida. En esta medida cabe decir, modificando parcialmente el dictum de $\mathrm{Hegel}^{31}$, que el que actúa defectuosamente es honrado como persona moral, esto es, como contraparte de un contrato, a través de la atribución de responsabilidad. Y no es necesario añadir fundamento alguno a favor de que solo la segunda alternativa de reacción al quebrantamiento de la norma es racional, prácticamente realizable y ventajosa para todos.

La culpabilidad jurídico-penal ya fue designada como una forma particularmente grave -que gatilla indignación- de falla personal, a saber, como una grave lesión del sentido de la justicia. Con el sentido de la justicia no es traído a colación elemento nuevo alguno; el mismo se deriva, antes bien, de las condiciones de la personalidad moral. El sentido de la justicia es el lado subjetivo de una moralidad orientada a principios pues designa el sentimiento de vinculación a principios constitutivos de interacciones justas ${ }^{32}$.

\footnotetext{
${ }^{30} \mathrm{Al}$ concepto de persona moral le es necesariamente propio, por ello, un elemento normativo. Sobre este problema, desde una perspectiva diferente, véase JESCHECK, Hans-Heinrich. Das Menschenbild unserer Zeit und die Strafrechtsreform [La idea de humanidad en nuestro tiempo y la reforma penal]. Tubinga, Alemania: Mohr (Siebeck), 1957, pp. 13 ss.; KaUfmanN, Arthur. Das Schuldprinzip [El principio de culpabilidad] -2a ed.- Heidelberg, Alemania: 1976, pp. 116 ss.

${ }^{31}$ Hegel, G.W.F. Grundlinien der Philosophie des Rechts [Bases de la filosofía del derecho]. HOFFMEISTER, Johannes (Ed.) 4a ed.- Hamburgo, Alemania: Meiner, 1955, p. 96 (\$ 100): "Que la pena sea vista en ello como su propio derecho, en esto el criminal es honrado como racional".

32 Acerca del sentido de la justicia véase especialmente RaWls, John, op. cit. (n. 5), pp. 493 ss.; el mismo, Gerechtigkeit als Fairneß [Justicia como equidad]. Alemania: 1977, pp. 125 ss.; véase también STROTZKA, Hans, en: PAUS, Ansgar (coord.). Werte, Rechte, Normen [Valores, derechos, normas]. Alemania: Graz-Wien-Köln: Butzon \& Berker Kevelaer/Styria, 1979, pp. 305 ss. En su análisis del sentido de la justicia, Rawls distingue tres formas de moralidad y, correspondientemente, tres formas de culpabilidad. La así llamada moral orientada a la autoridad tiene como objeto el amor y la confianza de los niños en sus autoridades, esto es, en sus padres, y se funda en la preocupación parental. La culpabilidad de autoridad aparece cuando el niño contraviene mandatos paternos -es decir, normalmente límites que él no entiende-, quien en razón de su vinculación psíquica a los padres asume, empero, el lugar de evaluación de estos y busca ser perdonado. La así llamada moralidad de orientación grupal constituye el segundo nivel en el desarrollo moral, siendo en primera línea determinada por amistad y refiriéndose a virtudes del trabajo en equipo: equidad, lealtad, confianza, integridad e imparcialidad. Existiendo las condiciones correspondientes, su quebrantamiento produce sentimientos de culpabilidad, que se manifiestan en la disposición a la reparación y al reconocimiento del actuar injusto, así como en la búsqueda de perdón. El tercer nivel del desarrollo moral lo representa la así llamada moral orientada a principios, la cual ya no se encuentra exclusivamente referida al bienestar y al reconocimiento de determinados seres humanos, sino que tiene como objeto
} 
"Un sistema en que cada cual posee sentido de la justicia y en el cual cada cual sabe del otro que este también lo posee", así sostiene Rawls acertadamente ${ }^{33}$, "es en sí mismo estable"; uno podría añadir: y solo entonces duraderamente estable.

Tal como la verdad es norma para proposiciones y la sinceridad es norma para afirmaciones, así la justicia es norma para la regulación de la interacción de personas morales. Es posible, sin más, que seres humanos de hecho apliquen reglas injustas en su interacción con otros, pero solo en tanto aquel que es tratado injustamente, de conformidad con la regla, no sea visto como igualmente valioso, por ejemplo, por motivos racistas; no es posible, sin embargo, que seres humanos de hecho se reconozcan recíprocamente como personas morales sin orientar sus interacciones sobre la base de principios de justicia.

Si uno tiene el sentido de la justicia por una condición básica de humanidad, entonces la culpabilidad merecedora de pena es, en el sentido en que aquí se la entiende, un signo de inhumanidad que gatilla indignación ${ }^{34}$.

\subsection{LA PENA COMO RETRIBUCIÓN DE CULPABILIDAD}

Ahora cabe retomar las reflexiones acerca de una pena orientada a la prevención general. El dilema del prisionero muestra que solo es racional seguir una norma ventajosa para todos si esta prestación es desempeñada por (casi) todos. Para que (casi) todos también hagan esto, sin embargo, no hay razón alguna, dado que es individualmente ventajoso quebrantar una norma que es generalmente seguida. La teoría de la prevención de intimidación intenta romper este círculo por la vía de oponer la amenaza y dado el caso también la ejecución de la pena al quebrantamiento de la norma. Mas el efecto estabilizador de una pena así entendida como medio coercitivo es bajo, tal como ya se argumentara, precisamente en la medida en que no se trate de asuntos poco significativos, sino ya de conflictos de libertad. Por ello, en el ámbito de reglas fundamentales de la interacción social no solo es más efectivo, sino también materialmente adecuado, poner la pena en referencia al nivel ético del quebrantamiento de la norma y desaprobar enérgicamente la inhumanidad expresada en el hecho, que lesiona el sentido de la justicia, a través de la irrogación de un mal.

Tampoco la más reciente $-y$ particularmente orientada hacia la teoría de sistemasteoría de la prevención general, la así llamada prevención general positiva ${ }^{35}$, conceptúa la

representaciones de derechos que son independientes de contingencias, es decir, en particular principios de justicia distributiva. Un sentido de la justicia así formado se expresa, de un lado, en el reconocimiento de instituciones justas, y de otro, en la colaboración activa o pasiva en tales instituciones. Produciéndose vulneraciones de estas, la indignación y el rencor, de una parte, así como los correspondientes sentimientos de culpabilidad, de otra, son explicados aquí de la mano de principios de justicia.

33 RAWLS, John, op. cit. (n. 32), p. 145.

34 Acertadamente dice HöfFe, Otfried, op. cit. (n. 16), p. 196, que "humanidad” está referida, como categoría crítica, a la negación y destrucción del sufrimiento, la necesidad y la injusticia.

35 Véase aquí especialmente JAKOBS, Günther. Schuld und Prävention [Culpa y Prevención]. Alemania: Mohr, 1976, pp. 3 ss. y passim; el mismo, Strafrecht AT [Derecho Penal Parte General]. Alemania: Gruyter, pp. 4 ss., con fundamentos ulteriores. -De modo esencialmente distinto se halla conceptuada la prevención general en HASSEMER, Winfried. Theorie und Soziologie des Verbrechens [Teoría y sociología del delito]. Frankfurt, Alemania: Athenäum-Fischer-Taschenbuch-Verlag, 1973, pp. 195 ss.; el mismo: Strafrechtsdogmatik und Kriminalpolitik [Dogmática jurídico penal y política criminal]. Alemania, Rowohlt, Reinbek bei Hamburg, 1974, pp. 123 ss.; el mismo, en: HASSEMER, LÜDERSEN, NAUCKE. Fortschritte im 
pena como un mero medio de intimidación. Ella ve en el quebrantamiento de la norma, antes bien, una frustración de expectativas, que resulta educativamente compensada por la vía de un traslado simbólico de los "costos del conflicto" al autor. El rendimiento explicativo de esta variante de la teoría de la prevención general es, en mi opinión, bajo. Ella no alcanza a ofrecer un fundamento para la frustración y así tampoco a identificar el daño que la culpabilidad habría de representar como objeto del "cómputo de costos". ¿Por qué ha de tomarse a mal el quebrantamiento de una norma, si es en todo caso ventajoso quebrantar normas, de modo tal que uno tendría que contar en cada momento con un quebrantamiento de normas?36 ¿O debería seguirse de suyo de la representación de que uno es subsistema de un sistema "derecho" que todos los demás subsistemas ya funcionan de modo sistémicamente estabilizador? Dicho brevemente: esta teoría más reciente no da cuenta adecuadamente del problema, porque ella se desentiende de su dimensión éticojurídica. "Frustración" designa el quebrantamiento de una norma elemental de la coexistencia de libertad para todos, en tanto el autor haya hecho mal uso de la confianza en él depositada como personal moral. Un delito de violación, por ejemplo, no desencadena una mera decepción por la inestabilidad de la norma, sino indignación por la inhumanidad del autor que lesiona el sentido de la justicia.

Para una teoría de la prevención general que atienda al factor prepositivo de estabilización de normas justas -esto es, al sentido de la justicia de sujetos que se reconocen recíprocamente como personas morales-, la pena es un reproche que responde a una lesión del sentido de la justicia, donde la irrogación del mal tiene que corresponderse simbólicamente con el peso ético-jurídico del quebrantamiento de la norma ${ }^{37}$. El reproche resulta así doblemente expresivo. Primariamente: es correcto seguir normas por mor de la justicia (efecto de integración). Secundariamente: no es conveniente quebrantar normas (efecto de intimidación).

Desde esta perspectiva, la pena no es una duplicación, carente de sentido, del mal ya provocado, dado el caso, por el autor. El nivel de referencia de la pena es, antes bien, el quebrantamiento de la norma prohibitiva de la causación del daño respectivo. Más precisamente: la irrogación del mal refleja invertidamente el depósito de confianza que el autor, a través de su reconocimiento como persona moral, ha recibido ex ante. El autor dilapida este depósito de confianza, que es necesario para el libre desenvolvimiento personal, a través del quebrantamiento de la norma; el mismo es reclamado de vuelta al autor, simbólicamente, mediante la pena. Recién y precisamente el carácter posteriormente retributivo de la pena hace posible otorgar libertad anticipadamente al autor, y ya una libertad que él

Strafrecht durch die Sozialwissenschaften? [iProgreso en el derecho penal a través de las ciencias sociales?]. Heidelberg, Alemania: 1983, pp. 57 ss. -Críticamente al respecto NAUCKE, Wolfgang, en: HASSEMER, LÜDERSEN, NAUCKE, Ibid., pp. 17 ss.; el mismo: Die Wechselwirkung zwischen Strafziel und Verbrechensbegriff [La correlación entre el fin de la pena y el concepto de delito]. Stuttgart, Alemania: F. Steiner Verlag Wiesbaden, , 1985, pp. 22 ss. -Pormenorizadamente acerca de las nuevas teorías de la prevención general, en lo cual no cabe entrar aquí, Neumann, Scroth. Neuere Theorien von Kriminalität und Strafe [Teorías modernas sobre la criminalidad y la pena]. Darmstadt, Alemania: Wissenschaftliche Buchgesellschaft, 1980 , pp. 88 ss.

${ }^{36}$ En este sentido ya KANT, Immanuel. Metaphysik der Sitten [Metafísica de las costumbres], en Studienausgabe, Alemania, No IV, 1968, pp. 424 s. (Rechtslehre $\$ 42$ ).

${ }^{37}$ Acerca de la relatividad de esta correspondencia véase también HEGEL, W.F.G., op. cit. (nota 31), pp. 188 s. (\$218). 
puede legítimamente pretender como persona moral, pero que también entraña la posibilidad de su mal uso.

Es oportuno ahora demarcar esta teoría de la retribución relativa de la así llamada teoría absoluta, que tiene su defensor filosófico más prominente en Kant. Que Kant tematice la noción de una pena absoluta para impedir que aquel a ser sancionado sea tratado como medio para un fin ${ }^{38}$, más allá de los recelos inequívocamente justificados que esa noción despierta, parece ser convincente. Pues Kant no puede derivar una interpretación de la pena como carente de fines a partir de su equiparación del derecho con la autorización de la coacción; como mero medio coercitivo la pena estaría necesariamente asociada a fines. Efectivamente, para Kant la pena no es un derivado del concepto de derecho, sino que ella es sistemáticamente previa: aparece en el contexto de la doctrina del bien supremo. Puesto que el comportamiento ético es fuente de felicidad bajo una representación racional, la unificación de un comportamiento antiético con la obtención o subsistencia de la felicidad ha de verse como un elemento perturbador de un orden de todas las acciones posibles. Restablecer este orden es racionalmente necesario, de modo que la pena es la consecuencia inmediata e incondicionada de cada vulneración de leyes prácticas; toda acción contraria a una ley práctica es, en otras palabras, merecedora de pena ${ }^{39}$. Es posible hacer aprovechable esta noción para la pena criminal si uno también adecua la coordinación externa del arbitrio a la idea de un estado de cosas en que se consuma aquello que es posible e incondicionadamente debido de conformidad con leyes prácticas. Uno puede seguir aquí a Kant, es decir, derivar la pena criminal del merecimiento de pena como elemento de la idea de razón práctica y ver su fin en el restablecimiento ideal del estado de consumación de una comunidad ética ${ }^{40}$. Pero con ello el derecho penal asumiría, en mi opinión, una tarea metafísica, la cual el mismo, realistamente -en particular con la vista puesta en el desarrollo de un correspondiente concepto de culpabilidad-, no está en posición de desempeñar ${ }^{41}$.

\section{DE LA LEGITIMACIÓN DE NORMAS DE SANCIÓN}

Las consideraciones precedentes tenían por objeto las condiciones necesarias para la legitimidad de la pena. La segunda de las preguntas enunciadas al comienzo consiste en si hay también condiciones suficientes y, dado el caso, delimitadoras del reforzamiento sancionatorio legítimo de normas de comportamiento. Esta pregunta es respondida afirmati-

\footnotetext{
${ }^{38}$ KANT, Immanuel, op. cit. (n. 36), p. 453 (Rechtslehre, Allegemeine Anmerkung E.I.).

39 Véase KANT, Immanuel. Kritik der praktischen Vernunft (Crítica a la razón práctica), en Studienausgabe, Alemania: No IV, 1956, pp. 144 ss., 150, 254 ss.

40 Para una adecuada reconstrucción de la doctrina de Kant véase especialmente HöFfE, Otfiried, En: BRANDT, Reinhard (coord.). Rechtsphilosophie der Aufklärung [Filosofía jurídica de la ilustración]. Alemania: Walter de Gruyter, 1982, pp. 335 ss.; NAUCKE. Kant und die psychologische Zwangstheorie Feuerbachs [Kant y la teoría de la coacción psicológica de Feuerbach]. Harburgo, Alemania: Hansischer Gildenverlag, 1962, pp. 12 ss.; OBERER, en: BrANDT, Reinhard op. cit., (n. 40), pp. 399 ss. ${ }^{41}$ Véase también Noll, Peter. Die ethische Begrüdung der Strafe [El fundamento ético de la pena]. Tübingen, Alemania: JCB Mohr, 1962, p. 6; también acerca de esto, y en contra de una crítica superficial a Kant, Wolff, E.A., ZStW 97 (1985), pp. 787 ss.
} 
vamente por Naucke, quien apoyándose en Kant sostiene la necesidad de un "auténtico" derecho penal, creyendo, de otra parte, poder delimitar este derecho penal de un derecho de intervención, utilitaristamente fundamentado, orientado al control social ${ }^{42}$. Este recurso a Kant no resulta, en mi opinión, sostenible. Que Kant conceptúe el hurto, la falsificación de moneda y medios de cambio, mas no la estafa y la apropiación ilícita, como crímenes (públicos) ${ }^{43}$, muestra la relatividad de las valoraciones, y esta relatividad se vuelve precisamente palpable cuando uno compara el rechazo de Kant a la fijación de una pena de multa ${ }^{44}$ a la injuria con la actual configuración de la injuria como delito cuya persecución requiere querella $(\$ 194$ StGB). Pero mirada más de cerca todavía, la distinción de Kant entre crímenes públicos, que caen bajo la jurisdicción de la justicia penal, y meros crímenes privados, sometidos a la justicia civil, no constituye una cuestión que se siga de un principio intemporal del derecho. De una parte, ya en el derecho romano la distinción entre crimen privatum y crimen publicum se formulaba desde puntos de vista pragmáticos ${ }^{45}$. De otra parte, el propio Kant interpretaba el crimen publicum utilitaristamente, a saber, con la vista puesta en el peligro para la seguridad del pueblo ${ }^{46}$.

En el hecho no habrá otra razón suficiente para el primer paso, consistente en reforzar una norma, por ejemplo la prohibición del homicidio, mediante pena, que una decisión político-criminal orientada a la prevención general ${ }^{47}$. Mas una vez desplegado este primer paso, la idea de prevención mediante retribución de culpabilidad adquiere una propia dinámica delimitadora ${ }^{48}$. Las normas de comportamiento reforzadas punitivamente han de tener un valor de reconocimiento comparable, esto es, referido a un sistema de libertades fundamentales. Si el homicidio simple y el hurto de uso de una bicicleta $(\$ 248$ StGB) son tratados de modo formalmente idéntico, entonces la prohibición del hurto de uso se ve revalorizada, pero así también resulta desvalorizada la prohibición del homicidio, y esto significa, a su vez, que el derecho penal en su conjunto resulta desvalorizado. El fin de la pena exige, por ello, que solo normas cuyo quebrantamiento sea indicio de una inhumanidad indignante sean reforzadas mediante pena. Cada introducción de una bagatela en el derecho penal trivializa a este, privándolo de la seriedad que el reproche de culpabilidad debería expresar.

\footnotetext{
42 Véase NAUCKE, Wolfgang, op. cit. (n. 35), pp. 34 ss.

43 KANT, Immanuel, op. cit. (n. 36), p. 452 (Rechtslehre, Allgemeine Anmerkung E.I.).

44 Ibid., p. 454. - Esta relatividad apoya al mismo tiempo la tesis ya defendida, más arriba (texto correspondiente a la nota 41), según la cual la determinación de la pena criminal no es realistamente practicable en tanto orientada al bien supremo, a menos que uno relativice el estándar para la culpabilidad y la retribución.

45 Véase para esto Oberer, op. cit. (n. 40), pp. 410 ss., con fundamentos ulteriores.

${ }^{46}$ Los crímenes públicos son aquellos a través de los cuales "la comunidad y no meramente una persona individual resulta amenazada”, KANT, Immanuel, op. cit. (n. 36). Lo mismo vale para el derecho de gracia tratándose de un crimen laesae maiestatis, derecho que no puede ser legítimamente ejercido "si a través de la liberación de pena pudiera generarse peligro para el pueblo en atención a su seguridad".

${ }^{47}$ En general acerca de la relación entre razón práctica e historicidad de las normas BUBNER, Rüdiger, op. cit. (n. 25), pp. 275 ss. - En tanto la legitimidad de la pena solo es condición necesaria, mas no suficiente, para el establecimiento normativo de un determinado tipo delictivo, entonces la asunción de que la pena es legítima en sí misma es por principio compatible con una eventual exigencia, fundamentada político-criminalmente, de abolición del derecho penal en su conjunto.

48 Acerca de la delimitación del derecho penal por medio de la idea de culpabilidad véase también KAUfMANN, Arthur , op. cit. (n. 30), p. 278.
} 
El recurso habitual al principio de ultima ratio ${ }^{49}$ es, frente a ello, de escaso rendimiento. Este principio falla ya cuando se trata de normas de peso comparable. Así permanece inexplicado, por ejemplo, por qué el hurto de uso de una bicicleta, mas no así el hurto de uso de una cortadora de césped, es punible. Aquí o bien está injustificada la incriminación del uno o la falta de incriminación del otro.

\section{DERECHO PENAL DE LA CULPABILIDAD Y PROTECCIÓN DE BIENES JURÍDICOS}

Estas consideraciones acerca de la legitimidad ético-jurídica de la pena habrán de cerrarse con dos observaciones críticas relativas a la política criminal contemporánea. Esta se halla pronunciadamente comprometida con una protección de bienes jurídicos lo más efectiva posible, pero pierde de vista con ello que este objetivo solo puede ser alcanzado mediatamente, a través de una prevención general que descanse en la retribución de culpabilidad, y en definitiva solo dentro de márgenes estrechos. Particularmente problemáticos son en este ámbito los así llamados delitos de peligro abstracto y las así llamadas condiciones objetivas de punibilidad. Las puestas en peligro abstractas son menoscabos de las condiciones de seguridad que aparecen como necesarias para una disposición despreocupada sobre bienes jurídicos, así, entre otros, el cuerpo, la vida, y cosas de valor. La mayoría de las normas de los delitos de peligro abstracto se hallan, con la vista puesta en la protección de bienes jurídicos, más allá de toda objeción posible, ante todo porque la seguridad constituye una idée directrice de nuestro tiempo ${ }^{50}$. En tal medida, parece indudable que determinadas normas de seguridad pueden legítimamente ser reforzadas mediante pena. Mas aquí emerge -si bien no en todos los caso- un problema serio. Quien menoscaba la seguridad de determinados bienes jurídicos no menoscaba, sin embargo, estos bienes mismos. En esta medida, el hecho no necesariamente será indicio de una lesión grave del sentido de la justicia, no obstante esto pueda ser el caso en ciertos ámbitos $^{51}$. Entre la culpabilidad de un homicida y -escogiendo un ejemplo actualmente relevante- la culpabilidad del participante en una demostración que porta -por la razón que sea- una máscara ${ }^{52}$, hay mundos de distancia. Estos hechos son incomparables sub specie inhumanidad. Andar encapuchado puede ser un menoscabo particularmente perturbador de la seguridad desde un punto de vista de táctica policial; mas ello es irrelevante para un derecho penal de la culpabilidad. La penalización del andar encapuchado desautoriza, de esto se trata, la seriedad ética del derecho penal: con ello se crea la impresión de que andar encapuchado sería una forma de matar, violar o robar, y con ello se crea asimismo la impresión de que el homicidio, la violación y el robo serían una forma -algo peor- de andar encapuchado.

\footnotetext{
${ }^{49}$ Véase para esto NAUCKe, Wolfgang. Strafrecht [Derecho Penal]. -5a ed.- Alemania: Metzner, 1987, pp. 53 s.

50 Véase KindHÄUSER, Urs, op. cit. (n. 21), pp. 277 ss., 287 ss.

51 Por ejemplo, tratándose del incendio agravado ( $\$ 306$ StGB).

52 Recientemente, y muy fundadamente acerca de la "prohibición de capuchas", JAHN, JZ 1988, pp. 545 ss.
} 
La depreciación del derecho penal a través de la trivialización de la noción de culpabilidad se ve hoy día ulteriormente acelerada, y ya gracias a un artificio legislativo. La prueba de los presupuestos subjetivos de la culpabilidad, en particular del dolo o la imprudencia subjetiva, resulta difícil. Puede resultar irritante, en el caso aislado, tener que dejar libre al presunto autor de un delito por falta de prueba del dolo. Pero puesto en perspectiva esto resulta tranquilizador, porque ello ofrece certeza en cuanto a que solo el efectivamente culpable, en el auténtico sentido del término, resultará condenado. Para una protección de bienes jurídicos que pretende ser lo más efectiva posible, sin embargo, las dificultades probatorias representan un desastre. Por ello se escogen determinados elementos del contexto de imputación y se los declara condiciones objetivas de punibilidad ${ }^{53}$. El ejemplo más crudo: el tipo de la embriaguez $(\$ 323 \mathrm{a} \text { StGB })^{54}$. De conformidad con este, alguien es penado por el consumo excesivo de alcohol si él después, en estado de embriaguez, realiza algún tipo delictivo sin culpabilidad y sin siquiera haberlo previsto. Ello es doblemente escandaloso, porque un comportamiento que está lejos de ser extremadamente inhumano, el consumo de alcohol, provee el pretexto para sancionar el quebrantamiento de una norma cometido sin culpabilidad.

Desde una perspectiva ética, los delitos de peligro abstracto y las condiciones objetivas de punibilidad representan un punto críticamente neurálgico del derecho penal. Una lucha férrea por incluir el derecho penal en una estrategia de humanidad no es compatible con la histeria de la política de la seguridad; la advertencia de Helmuth Mayer en cuanto al "exceso punitivo destructor del ser humano" 55 ha de ser tomada en serio alguna vez.

\section{REFERENCIAS BIBLIOGRÁFICAS}

BAIER, Kurt. Der Standpunkt Der Moral [El Punto de Vista de la Moral]. Düseldorf, Alemania, Patmos Verlag, 1974.

BARTUSCHAT, Wolfgang, En: HÖFFE (Coord.). Thomas Hobbes, Anthropologie Und Staatsphilosophie [Thomas Hobbes, Antropología y Filosofía del Estado]. Freiburg, Alemania, 1981.

Baurmann, Michael. Zweckrationalität Und Strafrecht, Argumente Für Ein Tatbezogenes Maßnahmerecht, [Racionalidad Instrumental y Derecho Penal]. Opladen, Alemania, Westdeutscher Verlag, 1987.

Bubner, Rüdiger. Handlung, Sprache, Vernunft, [Acción, Lenguaje, Razón]. Verlag, Alemania, Suhrkamp 1982.

Buchanan, James. Die Grenzen Der Freiheit [Los Limites de la Libertad]. Alemania, Mohr Siebeck, 1984.

Dennett, Daniel. Bedingungen Der Personalität [Condiciones de la Personalidad]. En: SIEP, Ludwig (Ed.). Identität Der Person [Identidad de la Persona]. Alemania, Basel-Stuttgart: Schwabe, 1983.

Frankena, William. Analytische Ethik [Ética Analitica]. München, Alemania, Deutscher Taschenbuch Verlag, 1972.

GÖssel, Karl Heinz, Festschr. F. Pfeiffer, 1988.

\footnotetext{
53 De hecho, las condiciones objetivas de punibilidad no constituyen un derivado del fin de la sanción, sino condiciones del injusto material; ellas han de quedar por lo menos cubiertas por criterios de imprudencia en el contexto de imputación; véase KindHÄUSER, Urs, op. cit. (nota 21), pp. 294 ss.; KAUFMAnN, Arthur, op. cit. (n. 30), pp. 247 ss.

${ }^{54}$ Véase KindhäUSER, Urs, op. cit. (n. 21), pp. 326 ss.

55 MAYER, Helmuth. Strafrechtsreform für heute und morgen [Reforma penal para hoy y mañana]. Alemania, Duncker \& Humblot, 1962, p. V.
} 
HART, H.L.A. Recht Und Moral. Göttingen, Alemania, Vandenhoeck \& Ruprecht Verlag, 1971.

Hassemer, Winfried. En: Hassemer, LÜdersen, Naucke. Fortschritte Im Strafrecht Durch Die Sozialwissenschaften? [¿Progreso en el Derecho Penal a Través de las Ciencias Sociales?]. Heidelberg, Alemania, 1983.

Hassemer, Winfried. Strafrechtsdogmatik Und Kriminalpolitik [Dogmática Jurídico Penal y Politica Criminal]. Rowohlt, Alemania, Reinbek Bei Hamburg, 1974.

HASSEMER, Winfried. Theorie Und Soziologie Des Verbrechens [Teoria y Sociología del Delito]. Frankfurt, Alemania, Athenäum-Fischer-Taschenbuch-Verlag, 1973.

Hegel, G.W.F. Grundlinien Der Philosophie Des Rechts [Bases de la Filosofia del Derecho]. Hoffmeister, Johannes (Ed.) 4ª Ed., Hamburgo, Alemania, Meiner, 1955.

Hobbes, Thomas. Leviathan. Editado por Iring Fetscher Frankfurt A. M, Alemania, Suhrkamp, 1984.

HOERSTER, Norbert. Utilitaristische Ethik Und Verallgemeinerung [Ética Utilitarista y Generalización]. Freiburg/München, Alemania, Verlag Karl Alber, 1971.

HÖFFE, Otfiried, En: BRANDT, Reinhard (Coord.). Rechtsphilosophie Der Aufklärung [Filosofía Jurídica de la Ilustración]. Alemania, Walter De Gruyter, 1982.

HÖFFE, Otfiried, Einführung In Die Utilitaristische Ethik [Introducción a la Ética Utilitarista]. München, Alemania, Klassische Und Zeitgenössische Texte, Beck, 1975.

Höffe, Otfiried. Ethik Und Politik [Ética y Politica]. Frankfurt, Alemania, Suhrkamp Taschenbuch Wissenschaft, 1979.

HöFfE, Otfiried. Politische Gerechtigkeit. Grundlegung Einer Kritischen Philosophie Von Recht Und Staat [Justicia Politica, Fundación de una Filosofía Critica del Derecho y el Estado]. Frankfurt, Alemania, Suhrkamp, 1987.

HÖfFe, Otfiried. Zur Ethik Öffentlicher Entscheidungsprozesse [Hacia una Ética en los Procesos de Decisión Pública]. En Alber - Reihe: Praktische Philosophie, Strategien Der Humanität, Freiburg, München, Alemania, 1975.

JAKOBS, Günther. Schuld Und Prävention [Culpa y Prevención]. Alemania, Mohr, 1976.

JeSCHeCK, Hans-Heinrich. Das Menschenbild Unserer Zeit Und Die Strafrechtsreform [La Idea de Humanidad en Nuestro Tiempo y la Reforma Penal]. Tubinga, Alemania, Mohr (Siebeck), 1957.

Journal Of Philosophy, Columbia University, No 68, Nueva York, Estados Unidos, 1971.

Kant, Immanuel. Kritik Der Praktischen Vernunft (Crítica a la Razón Práctica). En Studienausgabe, Alemania, No IV, 1956.

KanT, Immanuel. Metaphysik Der Sitten [Metafísica de las Costumbres]. En Studienausgabe, Alemania, No IV, 1968.

Kaufmann, Arthur. Das Schuldprinzip [El Principio de Culpabilidad]. 2a Ed., Heidelberg, Alemania, 1976.

KindhäUser, Urs, Gefährdung Als Straftat [Puesta en Peligro Como Delito], Klostermann, Alemania, Vittorio, 1989.

KÖHLER, Peter. Strafrecht At [Derecho Penal Parte General]. Alemania, Gruyter.

KöHLER, Peter. Neue Theorien Des Sozialkontrakts [Nuevas Teorias del Contrato Social]. Alemania, Dunker Und Humblot, 1987.

KÖHLER, Peter. Theorien Des Sozialkontrakts Als Rechtfertigungsmodelle Politischer Institutionen [Teorias Del Contrato Social Como Modelos de Justificación de Instituciones Politicas]. En: Theorie Der Normen [Teoría de las Normas]. Berlín, Alemania, Festgabe Für Ota Weinberger, 1984.

KraWietZ, W. Theorie Der Normen [Teoría de las Normas]. Berlín, Alemania, Festgabe Für Ota Weinberger, 1984. 
LÜDERSSEN, Klaus. Die Krise Des Öffentlichen Strafanspruchs [La Crisis de la Acción Penal Pública]. Frankfurt, Alemania, Würzburger Vorträge Zur Rechtsphilosophie, Rechtstheorie Und Rechtssoziologie Heft 10, 1989.

MACKIE, John. Ethik [Ética]. Alemania, Reclam Universal-Bibliothek, 1981.

MAYER, Helmuth. Strafrechtsreform Für Heute Und Morgen [Reforma Penal para Hoy y Mañana]. Alemania, Duncker \& Humblot, 1962.

NAUCKE, Wolfgang. Strafrecht [Derecho Penal]. 5a Ed., Alemania, Metzner, 1987.

NAUCKE, Wolfgang. Die Wechselwirkung Zwischen Strafziel Und Verbrechensbegriff [La Correlación entre el Fin de la Pena y el Concepto de Delito]. Stuttgart, Alemania, F. Steiner Verlag Wiesbaden, 1985.

NAUCKE, Wolfgang. Rechtsphilosophische Grundbegriffe [Conceptos Básicos de Filosofía del Derecho]. 2a Ed., Alemania, Luchterhand Verlag, 1986.

NAUCKE, Wolfgang. Kant Und Die Psychologische Zwangstheorie Feuerbachs [Kant y la Teoría de la Coacción Psicológica De Feuerbach]. Harburgo, Alemania, Hansischer Gildenverlag, 1962.

Neumann, Scroth. Neuere Theorien Von Kriminalität Und Strafe [Teorias Modernas sobre la Criminalidad y la Pena]. Darmstadt, Alemania, Wissenschaftliche Buchgesellschaft, 1980.

Noll, Peter. Die Ethische Begrüdung Der Strafe [El Fundamento Ético de la Pena]. Tübingen, Alemania, Jcb Mohr, 1962.

NozICK, Robert. Anarchie, Staat, Utopia [Anarquí, Estado y Utopía]. Frankfurt, Alemania, Moderne Verlagsgesellschaft 1976.

RAWLS, John. Eine Theorie Der Gerechtigkeit [Teoría de la Justicia]. Alemania, Suhrkamp, ,1975.

SEARle, John. Geist, Hirn Und Wissenschaft [Mentes, Cerebros Y Ciencia]. Frankfurt, Alemania, Suhrkamp, 1986.

SEARLE, John. Sprechakte [Actos de Habla]. Frankfurt, Alemania, Suhrkamp Verlag, 1983.

SINGER, Marcus. Verallgemeinerung In Der Ethik Zur Logik Moralischen Argumentierens [Generalización en la Ética, hacia una Lógica en la Argumentación Moral]. Frankfurt A. M., Alemania, Deutsch Suhrkamp, 1975.

Strotzka, Hans, En: PAUS, Ansgar (Coord.). Werte, Rechte, Normen [Valores, Derechos, Normas]. Alemania, Graz-Wien-Köln: Butzon \& Berker Kevelaer/Styria, 1979. 